\title{
Diversity analysis of begomovirus in Golden dewdrop (Duranta erecta) through PCR-RFLP
}

\author{
Maaz Ahmad $^{1}$, Luqman Amrao ${ }^{1}$, Shahab Habib ${ }^{1}$, Muhammad Zeshan Ahmed ${ }^{1}$, Adnan \\ Ahmed $^{2}$ and Salman Ghuffar ${ }^{1}$
}

${ }^{1}$ Dept. of Plant Pathology, University of Agriculture Faisalabad, Pakistan

${ }^{2}$ Dept. of Plant Pathology, PMAS Arid Agriculture University, Rawalpindi, Pakistan

$\bowtie$ For any information: ask.author@journalbinet.com, Received: 16.07.17, Revised: 24.09.17;

Available online: 14 October 2017.

\begin{abstract}
Golden dewdrop (Duranta erecta) is an ornamental plant which is commonly grown in Pakistan due to its natural beauty and medicinal properties. It is mainly grown in tropical and sub-tropical region. Golden dewdrop is known to suffer many diseases. Among all golden dewdrop leaf curl disease is caused by the begomovirusis very common. This study analyzed the DNA-A component of begomovirusin by using PCR-RFLP. For this purpose survey was conducted from ten different locations in UAF (University of Agriculture Faisalabad) from golden dewdrop plant according to the typical symptoms such as upward curling of leaves, darkening and thickening of veins, stunting of plant size. Infected samples were brought into Virology lab in CABB (Centre of Agricultural Biochemistry and Biotechnology). For DNA extraction CTAB method was used but DNA was not showed due to low concentration after quantification through spectrophotometer which was less than 100ng/ $\mu$ l. Therefore Rolling Circle Amplification method (RCA) was used for amplification of DNA-A component which only amplified two samples (D1 and D2) successfully. For polymerase chain reaction universal primers $\beta 01$ and $\beta 02$ was performed on RCA products for amplification of DNA-A component of begomoviruses which amplified the DNA at $2.8 \mathrm{kbp}$. For diversity analysis three commonly restriction enzyme Pst1, Sac1 and BamH1was used which restrict the DNA at different bp. Final conclusion of the analysis describe about the diversity of begomoviruses in golden dewdrop which emerging as an alternate host for begomoviruses.
\end{abstract}

Key Words: Begomovirus, Golden dewdrop, PCR, RCA and Restriction enzyme

Cite Article: Ahmad, M., Amrao, L., Habib, S., Ahmed, M. Z., Ahmed, A. and Ghuffar, S. (2017). Diversity analysis of begomovirus in golden dewdrop (Duranta erecta) through PCR-RFLP. Journal of Bioscience and Agriculture Research,15(01), 1260-1265.

Crossref: https://doi.org/10.18801/jbar.150117.155

Article distributed under terms of a Creative Common Attribution 4.0 International License.

\section{Introduction}

Golden dewdrop (Duranta erecta) belongs to the family Verbenaceae. Most commonly known as a hedge plant in Pakistan. In the world, it is commonly used as a decorative purposes, beside of its 
natural beauty. It is also used in an herbal medicine for treatment of oral infection and in South Africa, its fruit is used to cure the intestinal worms (Whistler, 2000). According to Sanz et al. (2000) viral diseases are the major factors which responsible for low production of crops. Among all viruses begomoviruses are one of the major threat especially for the cash crops. Mansoor et al. (2000) also described that begomoviruses are also responsible to cause the infection in tomato, ornamental plants, cucurbits and radish etc. Whitefly is the vector which act as a carrier to transmit the begomovirus from one plant to another plant. This virus is further subdivided into two types monopartite or bipartite consists of one or two circular ssDNA components but mostly consist of bipartite genome containing both DNA-A and DNA-B components. The size of these component rangingfrom 2.6-2.8 kb (Seal et al., 2006). The structure of DNA-A is circular DNA and has been reported for large number of viruses. While DNA-B component have greater sequence diversity therefor it is difficult to detect and isolate (Briddon and Stanley, 2006). Among both the DNA A component involved in the control of both viral and host gene expression and responsible for viral infection reported by (Patil and Dasgupta, 2006). Keeping in view the present study was conducted to attain diversity analysis of begomovirus through PCR-RFLP in Golden dewdrop (Duranta erecta).

\section{Materials and Methods}

Collection of diseased sample: Identification of disease was done on the basis of symptomology such as upward curling of vein thickening and darkening, stunting the plants. Infected young leaves were collected from ten different places in U.A.F shown in table 01 andthen carefully placed them in ice box and those were brought to virology lab in CABB (Centre of Agricultural Biochemistry and Biotechnology) department and were stored at $-80^{\circ} \mathrm{C}$ in a freezer for further studies.

\section{Table 01. Places of sample collection}

\begin{tabular}{lll}
\hline No. & Sample & Place of Collections \\
\hline 1 & D1 & Department of Plant Pathology \\
2 & D2 & Start of Corridor \\
3 & D3 & In front of V.C house \\
4 & D4 & Department of Computer science \\
5 & D5 & Institute of Soil and Environmental Science \\
6 & D6 & Office of Dean Faculty of Agriculture \\
7 & D7 & Department of Crop Physiology \\
8 & D8 & Institute of Horticulture Sciences \\
9 & D9 & Department of Veterinary Anatomy \\
10 & D10 & In front of Veterinary Diagnostic Lab \\
\hline
\end{tabular}

Isolation of total genomic DNA: After sample collection according to (Doyle and Doyle, 1990) the total genomic DNA was isolated by using CTAB method.

Rolling Circle Amplification (RCA): The spectrophotometer (Smart Spec TM Plus, BioRad) is used to determine the concentration of DNA at $260 \mathrm{~nm}$ absorbance. According to the quantity of genomic DNA was less than $100 \mathrm{ng} / \mu \mathrm{l}$. therefore rolling circle amplification (RCA) reaction was performed for amplification of DNA- A component followed by two scientists (Dean et al., 2001; Gusev et al., 2001).

Preparation of Agarose Gel: For conformation 1\% agarose gel was prepared for the running of total genomic DNA, PCR and RCA products etc. reported by (Lee et al., 2012).

PCR (Polymerase chain reaction) for Beta satellite Amplification: PCR is used for the amplification of DNA followed by (Sunter et al., 1990). In PCR UniversalPrimers were used for DNA- A component of begomovirus for amplification named as $\beta 01$ and $\beta 02$. For PCRamplification the list of ingredients and their composition as in $1 \mathrm{X}$ for one sample and in $4 \mathrm{Xcomposition} \mathrm{for} 4$ samples along with positive control containing cotton leaf curlvirus and anegative control without virus shown in Table 02. 
Table 02. PCR contents for 25 ul volume

\begin{tabular}{llll}
\hline No. & \multicolumn{1}{c}{ Contents } & \multicolumn{1}{c}{ X } & \multicolumn{1}{c}{$4 \mathrm{X}$} \\
\hline 1 & RCA Dilution & 2.5 & 10 \\
2 & Buffer & 2.5 & 10 \\
3 & $\mathrm{MgCl}_{2}$ & 1.5 & 6 \\
4 & dNTPs & 0.5 & 2 \\
5 & Forward primers (Begomo-F) & 0.5 & 2 \\
6 & Reverse primers (Begomo-R) & 0.5 & 2 \\
7 & $\mathrm{dH}_{2} \mathrm{O}$ & 16.7 & 66.8 \\
8 & Taq polymerase & 0.3 & 1.2 \\
\hline
\end{tabular}

RFLP (Restriction fragment length polymorphism) for diversity analysis of begomovirus: PCRRFLP analysis was done according to (Relman et al., 1996) six samples along with three positive control were taken. Restriction enzyme used for RFLP named as BmaH1, Pst 1and Sac 01.

\section{Results and Discussion}

Shoe flower is the alternative host of begomo virus and closely match with cotton leaf curl such as curling of leaf, thickening and darkening of veins, occasionally, samples were collected on the basis of these symptoms from ten different places of University of Agriculture, Faisalabad shows in Figure 01.

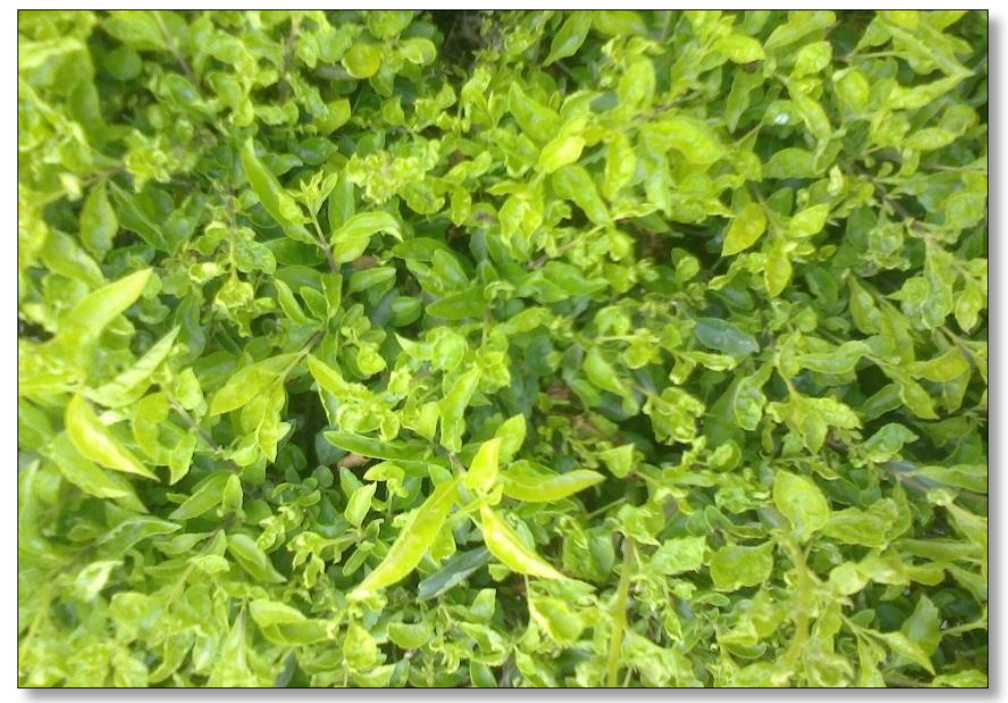

Figure 01. Golden Dewdrop plant showing symptoms of severe leaf curling.

DNA was extracted from 10 samples exhibit the typical symptoms of leaf curling but did not show any band due to the less concentration of DNA determined by the spectrophotometer which was less then 100ng/ $\mu$ l.Therefore Rolling Circle Amplification method was used to determine the DNA- A component of begomovirus. Two samples D1 and D2 was amplified by using Rolling Circle Amplification (RCA) method shown in Figure 02. 


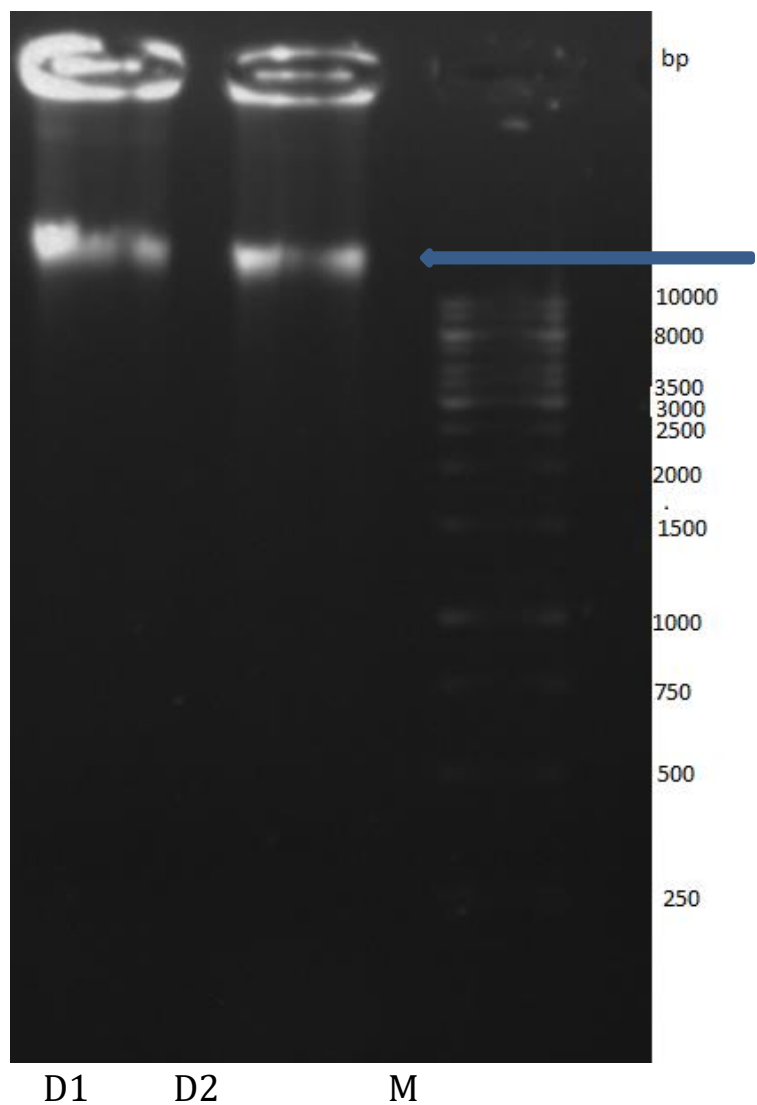

Figure 02. RCA amplification from two samples D1 and D2.

Polymerase chain reaction (PCR) on RCA products

Two universal primers such as $\beta 01$ (CCGGTACCACTACGCTACGCAGCAGCC) and $\beta 02$ (CCGGTACCTACCCTCCAGGGGTACAC) were used for PCR amplification of RCA product While CLCuV was used as positive control shown in Figure 03.

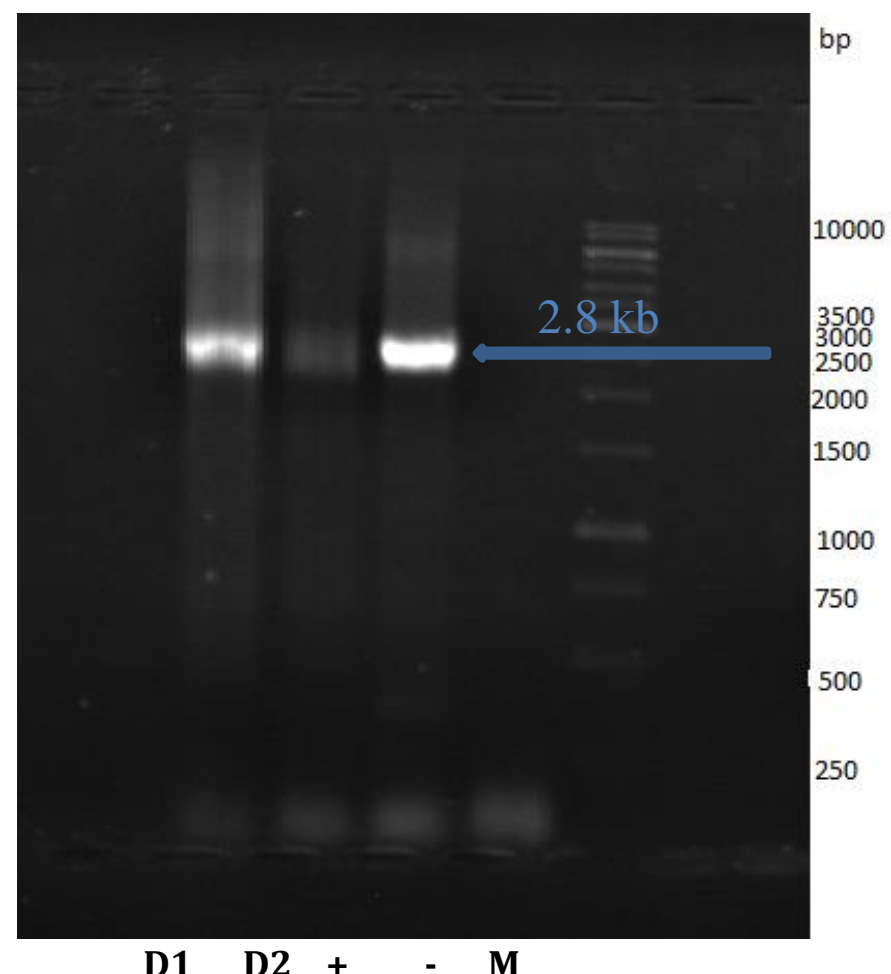

Figure 03. Gel picture of PCR after RCA. Fragment size of D1 and D2 samples is $2.8 \mathrm{~kb}$. 


\section{Diversity analysis through PCR-RFLP}

According to analysis.There was no Restriction observed in D1 sample with Pst1 enzyme while in case of D2fragment was restricted into $2 \mathrm{~kb}$ and $0.97 \mathrm{bp}$. In second restriction enzyme Sac1, D1 fragment was restricted into $2.8 \mathrm{~kb}$ while in D2 with same Sac1, fragment was restricted into $1.2 \mathrm{~kb}$ and $0.75 \mathrm{~kb}$. In case of D1 with BamH1, fragment was restricted into $2.5 \mathrm{~kb}$ while in D2, fragment was restricted at $2.8 \mathrm{~kb}$

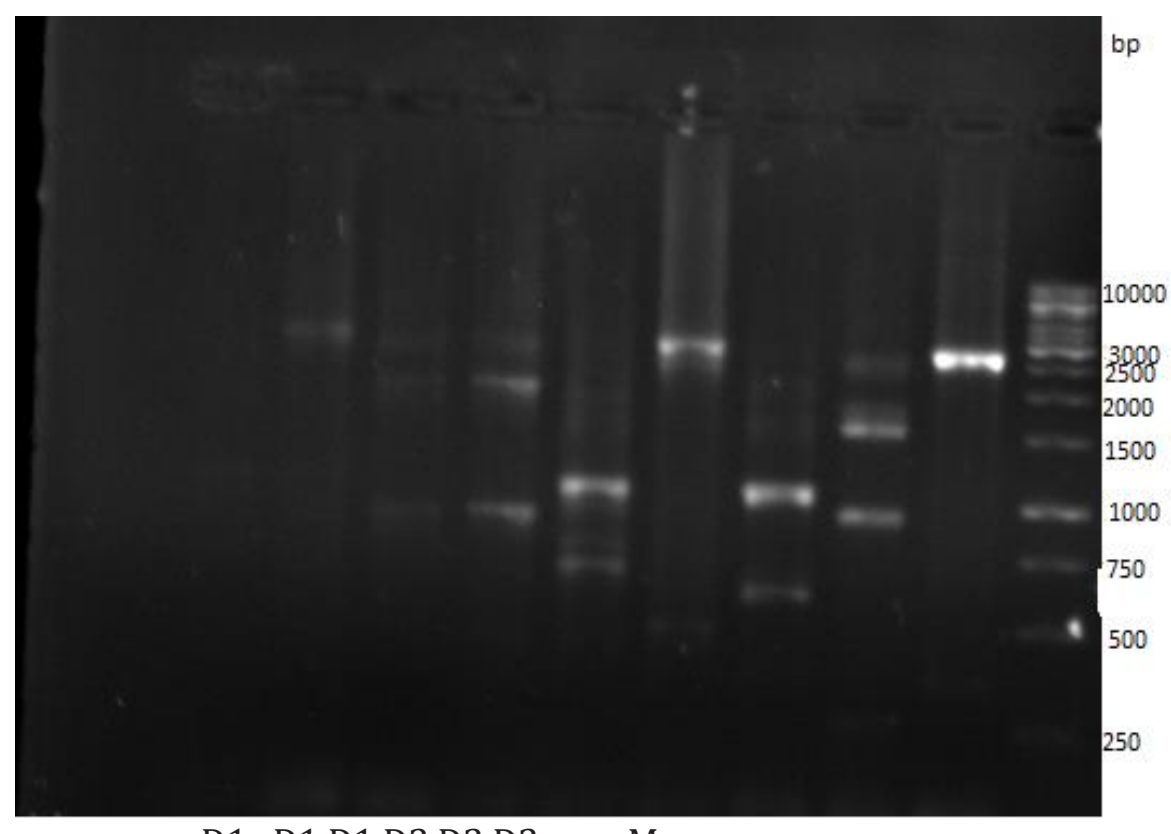

D1 D1 D1 D2 D2 D2+++ M

Pst1 Sac1 Bam H1 Pst1 Sac1 Bam H1

Figure 04. Gel picture of restriction from PCR samples. CLCuV was used as positive control.

\section{Conclusion}

Rolling Circle Amplification (RCA) method was used for amplification of circular molecules present in total DNA. In this method, Phi-29 DNA polymerase enzyme was used to amplify circular DNA molecules. Circular molecules were amplified through RCA in D1 and D2 samples, confirmed by gel electrophoresis. RCA products were restricted with Pst1, Sac1 and BamH1 restriction enzymes. Fragments of $2.8 \mathrm{~kb}$ were observed in D1 and D2 samples which revealed that begomoviruses are prevailing in samples.

\section{References}

[1]. Briddon, R. W. and Stanley, J. (2006). Sub-viral agents associated with plantinfecting singlestranded DNA viruses. Virology, 344, 198-210. https://doi.org/10.1016/j.virol.2005.09.042

[2]. Dean, F. B., Nelson, J. R., Giesler, T. L. and Lasken, R. S. (2001). Rapid Amplification of Plasmid and Phage DNA Using Phi29 DNA Polymerase and Multiply-Primed Rolling Circle Amplification. Genome Research, 11(6), 1095-1099. https://doi.org/10.1101/gr.180501

[3]. Doyle, J. J. and Doyle, J. L. (1990). Isolation of plant DNA from fresh tissue. Focus. 12, 13-15.

[4]. Gusev, Y., Sparkowski, J., Raghunathan, A., Ferguson, H., Montano, J., Bogdan, N. and Wheeler, V. (2001). Rolling Circle Amplification: A New Approach to Increase Sensitivity for Immunohistochemistry and Flow Cytometry. The American Journal of Pathol, 159(1), 63-69. https://doi.org/10.1016/S0002-9440(10)61674-4

[5]. Lee, I. M. D., Gundersen-Rindal, E., Davis, R. E. and Bartoszyk, I. M. (2012). Revised classification scheme of phytoplasmas based onRFLP analyses of 16S rRNA and ribosomal protein genesequences. Int J Syst Bacteriol, 48, 1153-1169. https://doi.org/10.1099/00207713-48-4-1153

[6]. Mansoor, S., Briddon, R. W., Bull, S. E., Bedford, I. D., Bashir, A., Hussain, M., Saeed, M., Zafar, M. Y., Malik, K. A., Fauquet, C. and Markham, P. G. (2003). Cotton leaf curl disease is associated with multiple monopartite begomoviruses supported by single DNA. Archives of Virol, 148, 1969-1986. 
https://doi.org/10.1007/s00705-003-0149-y

[7]. Patil, B. L. and Dasgupta, I. (2006). Defective Interfering DNAs of Plant Viruses. Critical Reviews in Plant Sci, 25, 47-64. https://doi.org/10.1080/07352680500391295

[8]. Relman, D. A., Schmidt, T. M., Gajadhar, A., Sogin, M., Cross, J., Yoder, K., Sethabutr, O. and echeverria, P. (1996). Molecular phylogenetic analysis of Cyclospora, the human intestinal pathogen, suggests that it is closely related to Eimeria species. J. Infect. Dis, 173, 440-445. https://doi.org/10.1093/infdis/173.2.440

[9]. Sanz, A. I., Fraile, A., García-Arenal, F., Zhou, X., Robinson, D. J., Khalid, S., Butt, T. and Harrison, B. D. (2000). Multiple infection, recombination and genome relationships among begomovirus isolates found in cotton and other plants in Pakistan. J. of General Virol, 81, 1839-1849. https://doi.org/10.1099/0022-1317-81-7-1839

[10]. Saunders, K., Norman, A., Gucciardo, S. and Stanley, J. (2004). The DNA $\beta$ satellite component associated with ageratum yellow vein disease encodes an essential pathogenicity protein $(\beta C 1)$. Virol, 324, 37-47. https://doi.org/10.1016/j.virol.2004.03.018

[11]. Sunter, G., Hartitz, M. D., Hormuzdi, S. G., Brough, C. L. and Bisaro, D. M. (1990). Genetic analysis of tomato golden mosaic virus: ORF AL2 is required for coat protein accumulation while ORF AL3 is necessary for efficient DNA replication. Virol, 179, 69-77. https://doi.org/10.1016/0042-6822(90)90275-V

[12]. Seal, S. E., van den Bosch, F. and Jeger, M. J. (2006). Factors influencing begomovirus evolution and their increasing global significance: implications for sustainable control. Critical Reviews in Plant Sciences, 25, 23-46. https://doi.org/10.1080/07352680500365257

[13]. Whistler, W. A. (2000). Tropical ornamentals, a guide. Timber Press, Inc., Portland. p. 542.

\section{HOW TO CITE THIS ARTICLE?}

\section{Crossref: https://doi.org/10.18801/jbar.150117.155}

\section{APA (American Psychological Association)}

Ahmad, M., Amrao, L., Habib, S., Ahmed, M. Z., Ahmed, A. and Ghuffar, S. (2017). Diversity analysis of begomovirus in Golden dewdrop (Durantaerecta) through PCR-RFLP. Journal of Bioscience and Agriculture Research,15(01), 1260-1265.

\section{MLA (Modern Language Association)}

Ahmad, M., Amrao, L., Habib, S., Ahmed, M. Z., Ahmed, A. and Ghuffar, S. "Diversity analysis of begomovirus in Golden dewdrop (Durantaerecta) through PCR-RFLP". Journal of Bioscience and Agriculture Research, 15.01(2017): 1260-1265.

\section{Chicago and or Turabian}

Ahmad, M., Amrao, L., Habib, S., Ahmed, M. Z., Ahmed, A. and Ghuffar, S. "Diversity analysis of begomovirus in Golden dewdrop (Durantaerecta) through PCR-RFLP". Journal of Bioscience and Agriculture Research,15 no.01(2017):1260-1265.

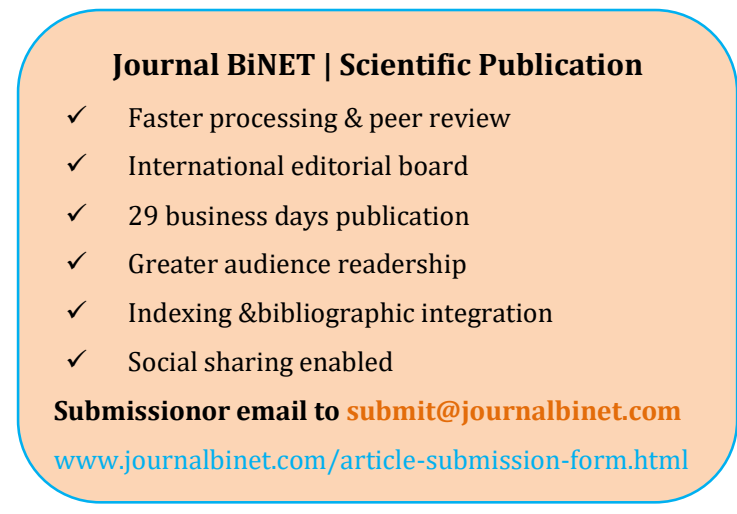

